\title{
Meta
}

Journal des traducteurs

Translators' Journal

\section{Weissbort, D. and A. Eysteinsson (eds.) (2006) : Translation - Theory and Practice : A Historical Reader, Oxford/New York, Oxford University Press, X + 649 p.}

\section{Serge Marcoux}

Volume 52, numéro 2, juin 2007

URI : https://id.erudit.org/iderudit/016080ar

DOI : https://doi.org/10.7202/016080ar

Aller au sommaire du numéro

Éditeur(s)

Les Presses de l'Université de Montréal

ISSN

0026-0452 (imprimé)

1492-1421 (numérique)

Découvrir la revue

Citer ce compte rendu

Marcoux, S. (2007). Compte rendu de [Weissbort, D. and A. Eysteinsson (eds.) (2006) : Translation - Theory and Practice: A Historical Reader, Oxford/New

York, Oxford University Press, X + 649 p.] Meta, 52(2), 362-365.

https://doi.org/10.7202/016080ar

Ce document est protégé par la loi sur le droit d'auteur. L'utilisation des services d'Érudit (y compris la reproduction) est assujettie à sa politique d'utilisation que vous pouvez consulter en ligne.

https://apropos.erudit.org/fr/usagers/politique-dutilisation/
Cet article est diffusé et préservé par Érudit.

Érudit est un consortium interuniversitaire sans but lucratif composé de l'Université de Montréal, l'Université Laval et l'Université du Québec à Montréal. Il a pour mission la promotion et la valorisation de la recherche. https://www.erudit.org/fr/ 
Weissbort, D. and A. Eysteinsson (eds.) (2006): Translation - Theory and Practice: A Historical Reader, Oxford/New York, Oxford University Press, X + 649 p.

Fidèles à leur image de marque, les Presses de l'Université d'Oxford nous offrent une anthologie de qualité qui, alliant présentation classique et approche novatrice, présente au lecteur l'histoire et l'apport de la traduction à la tradition littéraire de langue anglaise, de l'Antiquité à nos jours. Elle constitue ainsi le complément idéal de The Oxford Guide to Litterature in English Translation ${ }^{1}$ et de The Oxford Book of Verse in English Translation ${ }^{2}$.

Prenant comme thème central le texte source hébreu et la traduction grecque $e^{3}$ de la parabole biblique de la tour de $\mathrm{Babel}^{4}$, les rédacteurs retraceront tout au cours des siècles les différentes traductions qu'en feront Ælfric (env. 1050) en anglais ancien, William Tyndale (1525) en anglais médiéval, Martin Luther (1534) en allemand, la King James' Bible (commencée en 1604) en anglais classique et Everett Scott (1995) en anglais contemporain, illustrant en cours de route de quelle manière celles-ci reflétaient la conception que chaque époque se faisait de la traduction.

Pour chaque traductrice ou traducteur retenu, les rédacteurs donnent un bref aperçu du contexte historique dans lequel elle ou il a vécu, résument sa carrière et citent divers passages où se révèle sa conception de la traduction. Dans la deuxième partie du livre, et plus particulièrement alors que nous nous rapprochons des années 1960 et que se développe une théorie de la traduction, les notes des rédacteurs se font plus brèves et laissent traductrices et traducteurs exposer dans leurs textes comment ils conçoivent leur travail.

Le premier chapitre couvre une période d'environ 1500 ans, allant des traducteurs latins de l'époque classique, tels Cicéron et Pline le Jeune, aux traducteurs de l'Église primitive, période au cours de laquelle on traduit généralement du grec vers le latin.

Déjà, à cette période, se manifeste l'opposition traditionnelle entre fidélité au texte source et fidélité à la pensée de l'auteur. À une époque où Rome devient maîtresse de la Méditerranée et cherche à affirmer son autonomie vis-à-vis de la culture grecque, il ne sera pas surprenant de voir Cicéron se faire le champion d'une approche plus littéraire que littérale de la traduction postulant que l'élève doit chercher à surpasser son maître et non à le copier. Au contraire, avec l'arrivée du christianisme et l'obligation de traduire la parole de Dieu, «une» à travers toutes les langues dans lesquelles elle s'exprime, saint Augustin ira jusqu'à préférer la traduction de la Septante, dont les auteurs, selon la tradition, auraient été guidés par l'Esprit saint lui-même, aux textes sources en hébreu et en araméen. Saint Jérôme, pour sa part, hésita longtemps entre l'esthétisme cicéronien et l'ascétisme chrétien, pour conclure, à tout le moins en ce qui concernait les saintes Écritures, que non seulement les mots devaient être traduits littéralement, mais que même leur ordre dans la phrase devait être respecté.

Ce n'est qu'à partir du roi Alfred (871-899), que nous assistons aux premières traductions du latin vers le vieil anglais. Les traducteurs, travaillant dans les milieux ecclésiastiques, feront de la Bible et autres textes religieux le fondement de leur travail. Mais dans cette langue qui se crée et évolue rapidement, on assiste déjà, dans les quelque cinq cents ans qui séparent le roi Alfred de John of Trevisa (1326-1412), à une évolution considérable des traductions faites à partir d'un même texte, tant sur le plan de la langue que de la philosophie qui préside à l'approche traductrice.

Le deuxième chapitre ne couvre qu'une période de deux siècles et demi (1550-1800). Cependant cette période, qui inclut à la fois la Réforme et la Renaissance, peut être considérée comme l'âge d'or de la traduction: si la Réforme continuera la longue tradition des traductions bibliques, la Renaissance, elle, ramènera à l'avant-scène les grands classiques grecs et romains.

Martin Luther, en allemand, William Tyndale, en anglais, constituent les principales figures de la traduction biblique. Tous les deux se distingueront de leurs prédécesseurs en retournant aux textes sources hébreux et grecs et en ayant comme préoccupation essentielle 
de produire un texte adapté à leur public cible, souvent peu instruit, quitte à ajouter des mots qui ne se trouvent pas dans le texte source, ce qui leur vaudra d'être traités d'hérétiques par les "papistes»; Tyndale finira du reste sur le bûcher en 1536. La version subséquente, dite "version autorisée du roi Jacques», fruit des travaux de cinquante-quatre érudits convoqués par Jacques $I^{\text {er }}$, fut publiée en 1611. Contrairement à la bible de Douay-Reims (1610), destinée aux catholiques de Grande-Bretagne et d'Irlande, et rédigée à partir d'une traduction, celle de la Vulgate, la King James version prend comme textes de départ les textes originaux et adopte un style et une langue accessibles à tous.

Avec le début de la Renaissance, le latin redeviendra la langue à partir de laquelle ou vers laquelle se feront d'innombrables traductions; un livre sur dix du reste est écrit directement en latin comme l'Utopia de Thomas More (1516). Le français de Joachim du Bellay (1522-1560) ou l'anglais d'Arthur Golding (1536-1606) demeurent encore deux langues assez frustres qui ne permettent pas de transmettre la richesse de poésie ou de sentiment exprimée par les textes originaux. D'où la tendance, chez les écrivains et traducteurs comme John Dryden, Alexander Pope et Samuel Johnson, d'adopter à l'endroit des auteurs latins le même conseil que Cicéron donnait à l'endroit des auteurs grecs, à savoir que le sens du texte devait primer les mots avec lesquels il était rédigé.

Autre trait distinctif de l'époque: l'émergence de traductrices. Si elles ne sont que dixneuf au XVI ${ }^{\mathrm{e}}$ siècle, leur nombre aura considérablement augmenté au XVII ${ }^{\mathrm{e}}$ alors que l'instruction se généralise et que les dames de la haute société commencent à parler avec aisance le latin et diverses autres langues modernes. Parmi celles-ci, mentionnons Katherine Phillips (1631-1664) qui fut la première femme poète et dramaturge à remporter un succès certain, Lucy Hutchinson (1620-?), traductrice du poète latin Lucrèce, et Aphra Ben (?1640-1689) qui fut probablement la première dramaturge féminine à pouvoir vivre de sa plume.

Le XIX ${ }^{e}$ siècle nous ramène en Allemagne romantique (Goethe, Schleiermacher, Humboldt) et en Angleterre victorienne (Arnold, Newman, Blackie) où l'opposition aux méthodes de traduction libre représentée par la tradition française et les «belles infidèles» commence à s'organiser. On assiste en même temps aux premières traductions d'œuvres littéraires «populaires» en provenance d'autres langues européennes comme le danois et l'italien ou même indo-aryennes aux confins de l'Empire britannique.

La deuxième partie du volume, de longueur à peu près égale à la première, sera consacrée aux traducteurs du $\mathrm{xx}^{\mathrm{e}}$ siècle, la première partie couvrant la période de Pound à Nabokov, la deuxième celle des traducteurs contemporains. L'internationalisation des grands courants de pensée se manifeste par un nombre de plus en plus grand de traducteurs pour qui l'anglais n'est plus nécessairement la langue maternelle (Jiř̌i Levý, George Steiner, Vladimir Nabokov, etc.). Ne pouvant résumer ici les quelque trente-sept traducteurs et traductrices présentés dans cette section du volume, nous nous contenterons de trois exemples pour chaque période, choisis de façon à illustrer le vaste éventail de cultures, de langues et de traditions que représente la traduction contemporaine.

Lorsque Ezra Pound (1885-1972) se mit à la traduction, au début des années 1910, il était encore d'usage de rendre le caractère antique de textes anciens au moyen d'archaïsmes et de procédés grammaticaux tels hath et methink. Pound fut sans doute le premier à suggérer l'utilisation d'un style moderne aux tons neutres et mi-formalistes pour communiquer à la fois l'impression du temps passé et de l'intemporel. De plus, à un moment où les traductions étaient considérées avec suspicion, il défendit l'apport de celles-ci à la littérature anglaise, particulièrement durant la période élisabéthaine. Pour Pound, la traduction est une forme de critique littéraire puisqu'elle permet aux lecteurs d'accéder à des œuvres littéraires d'importance et aux écrivains de trouver, à travers la voix de leurs collègues étrangers, leur propre voix.

Argentin d'origine, éduqué en Europe, Jorge Luis Borges (1899-1986) fut aussi un brillant universitaire anglo-saxon. Écrivain, poète, critique, et homme de lettres, il traduisit 
en espagnol The Happy Prince d'Oscar Wilde alors qu'il n'avait que dix ans. Tout comme Nabokov, Borges combine un intérêt pour la culture de son pays d'origine avec des intérêts plus universels; son multilinguisme se traduit par une propension à jouer avec les mots et leur signification. Mais alors qu'on note chez Nabokov comme chez Joyce une évolution vers des œuvres de plus en plus élaborées, le style de Borges demeurera celui d'un «miniaturiste», se dirigeant vers une transparence et un naturel à l'antithèse du style ampoulé des symbolistes. Pour Borges, une bonne traduction peut dépasser en qualité le texte original et des versions potentiellement contradictoires d'une même œuvre peuvent s'avérer également valables.

Né dans une famille aristocratique de Saint-Pétersbourg où l'on parlait indifféremment le russe, le français et l'anglais, Vladimir Vladimirovich Nabokov (1899-1977) put lire et écrire l'anglais avant même le russe. Chassé de Russie par la révolution, Nabokov et sa famille séjournèrent successivement en Grande-Bretagne, en Allemagne et en France avant de s'installer aux États-Unis où ce dernier créa le Département d'études russes au Wellesley College en 1941. Romancier affectionnant les jeux de mots et les intrigues complexes, Nabokov fut aussi un traducteur de génie controversé qui voyait dans la traduction une sorte de synthèse culturelle où le passage d'une langue à l'autre se comparerait au lent voyage de nuit d'un village vers un autre à la seule lueur d'une bougie. Les traductions de ses propres œuvres, avec la collaboration occasionnelle de son fils Dimitri, lui valut toutefois d'être accusé de prôner la traduction littérale pour les œuvres des autres, mais de s'accorder une liberté beaucoup plus grande lorsqu'il s'agissait de ses propres textes.

La dernière section du livre s'ouvre avec les années 1960 alors que la traduction devient une discipline universitaire. L'un des ouvrages qui fera date en la matière est After Babel: Aspects of Language and Traduction de George Steiner (né en 1929) qui, dépassant la seule traduction, traite également du phénomène de la compréhension, de l'interprétation, des communications et des phénomènes reliés à l'herméneutique. Pour Steiner, tout traducteur est essentiellement un interprète qui, dans un langage où règne la polysémie, doit faire un choix entre des différences allant de la nuance à l'antithèse. Pour ce grand Européen d'origine juive qui vécut les affres du fascisme aussi bien que du communisme, des mots comme paix, liberté, progrès et volonté populaire, présents dans le vocabulaire des régimes totalitaires aussi bien que dans celui des démocraties, ont des sens qui diffèrent profondément d'un régime à l'autre. Traduire un texte stalinien avec le vocabulaire d'une société libérale ne peut que provoquer la confusion. Tout modèle de communication constitue de la sorte un modèle de traduction tant sur le plan paradigmatique que syntaxique, car aussi bien les individus et les sociétés que les époques interprètent la réalité d'une manière qui leur est propre.

Originaire de l'Inde, Gayatri Chakravorty Spivak (née en 1942) fit ses études en Inde et aux États-Unis. Elle a traduit, entre autres, diverses œuvres de Mahasweta Devi, écrivaine née en 1926 au Bengale oriental (aujourd'hui le Bengladesh). Elle est toutefois mieux connue pour sa traduction du livre De la grammatologie (1967), écrit par le philosophe français Jacques Derrida. Pour elle, la traduction n'est pas simplement un échange textuel entre deux langues, mais également un échange entre deux cultures, chacune ayant atteint un niveau de développement différent. Dès lors, on ne peut jamais être certain qu'à un changement de «signifiant» corresponde un changement identique de «signifié», car toute traduction implique non seulement un transfert, mais aussi une transformation du message entre cultures différentes. Bien plus qu'un échange interlinguistique, la traduction constitue ainsi un échange entre cultures, nations, continents, races et genres. Si bien que la traduction des œuvres de Mahasweta Devi obligera madame Spivak à se définir face au féminisme et au postcolonialisme tels qu'ils se présentent dans la société bangladeshi.

Né en Arabie Saoudite et éduqué au Pakistan, Talal Asad, professeur émérite d'anthropologie à l'Université de New York, pousse encore plus loin cette analyse des rapports de forces entre langues ayant atteint des niveaux de développement différents. Il montre com- 
ment, depuis le début du XIX ${ }^{\mathrm{e}}$ siècle, le nombre croissant d'ouvrages scientifiques, historiques et sociologiques traduits de langues européennes vers l'arabe ont conduit à une modification lexicale, grammaticale et sémantique de cette langue, qui l'amène à se rapprocher progressivement des langues de départ. Le capitalisme industriel transforme ainsi non seulement les modes de production, mais également l'approche de la connaissance et le style de vie du tiers-monde et de ses formes de langages. Et plus le fossé est grand entre la langue de départ et la langue d'arrivée, plus grand aussi est le danger pour le traducteur de rendre explicite pour le lecteur ce qui reste implicite dans une culture primitive. Dans ce cas, le traducteur risque fort de devenir l'auteur véritable du texte traduit, cédant à la tentation de facilité consistant à rapprocher la culture trouvée dans le texte original de la culture de son lecteur plutôt que, tâche beaucoup plus difficile, d'amener son lecteur à se pénétrer de la culture de l'œuvre originale, que celle-ci soit orale ou écrite.

Translation - Theory and Practice nous offre à la fois un passionnant voyage de découverte de la traduction au fil des siècles ainsi qu'un remarquable abrégé des théories qui lui sont associées et qui oscillent depuis l'Antiquité entre la fidélité à la pensée de l'auteur et le respect dû au texte de départ.

Le seul reproche que nous pourrions adresser à cet ouvrage est de ne pas préciser, sauf pour quelques remarques dans la postface, les critères qui ont présidé au choix des traducteurs retenus. Si certains, comme Martin Luther ou Friedrich Schleiermacher, s'imposaient dans la première période, on ne peut en dire autant de ceux du $\mathrm{xx}^{\mathrm{e}}$ siècle, surtout lorsqu'il s'agit d'auteurs pour qui la traduction n'était pas la principale activité.

Par ailleurs, le lecteur féru de poésie sera heureux de trouver dans cette anthologie de nombreuses pages consacrées à la traduction de cette forme littéraire et aux difficultés épouvées par les traducteurs soucieux à la fois de sonorité et de sémantique chaque fois qu'il doivent rendre et le sens et la musicalité d'un texte.

Serge Marcoux

Université de Montréal, Montréal, Canada

\section{NOTES}

1. Peter France (ed), The Oxford Guide to Literature in English Translation, Oxford, Oxford University Press, 2000.

2. Charles Tomlinson (ed), The Oxford Book of Verse in English Translation, Oxford, Oxford University Press, 1980.

3. Généralement appelée «La Septante».

4. Genèse, chapitre 11, versets 1-9.

Balliu, C. (2005): Les confidents du Sérail. Les interprètes français du Levant à l'époque classique, Beyrouth, Université de Saint-Joseph, coll. «Sources-Cibles», 193 p.

La traduction (traduction écrite) et l'interprétation (traduction orale) n'ont pas toujours fait l'objet d'une distinction technique et méthodologique aussi claire et nette que maintenant. En effet, ce n'est finalement qu'au $\mathrm{xx}^{\mathrm{e}}$ siècle que l'interprétation a pris cette dimension qualitative et professionnelle qui l'a transformée à part entière en activité exclusive et autonome: la naissance et le développement du concept, de la pratique et de la pédagogie de l'interprétation de conférence.

À l'époque classique, par contre, la conception de l'interprétation était encore nettement plus «riche». Elle dépassait de loin les «fonctionnalismes» restrictifs des définitions, des 